\title{
MOISTURE DAMAGE EVALUATION USING ENERGY BASED RESPONSES
}

\author{
Amir MEHRARA, Ali KHODAII \\ Department of Civil and Environmental Engineering, \\ Amirkabir University of Technology, 404 Hafez ave., Tehran, Iran
}

Received 10 Dec 2013; accepted 30 Jun 2014

\begin{abstract}
Monotonic Indirect Tensile tests were performed on asphalt concrete mixtures made of two different types of aggregates. Since the environmental condition is a determining factor in propagation of moisture damage, the effects of temperature and aging were also observed. Three levels of temperature including $4.4{ }^{\circ} \mathrm{C}, 21.1{ }^{\circ} \mathrm{C}$ and $37.8{ }^{\circ} \mathrm{C}$ were used in testing. In order to consider the effect of aging, part of the samples were aged according to AASHTO R 30-02 (2010). The parameters of fracture energy, elastic energy and dissipated creep strain energy were obtained for dry and moisture conditioned samples. The sensitivity of the responses to testing parameters was investigated using analysis of variance methods and visual inspections. According to the results, common energy responses cannot be used as realistic criteria to evaluate asphalt mixtures' moisture damage. To overcome the inadequacy of common energy based responses, modified energy responses were defined using conventional energy based responses normalized by specimens' failure strain. The analysis of variance showed that the modified energy responses can effectively evaluate the mixtures' moisture and temperature susceptibility.
\end{abstract}

Keywords: fracture energy, creep strain energy, elastic energy, asphalt concrete, moisture damage, indirect tensile test.

\section{Introduction}

There are several types of tests that have been used to evaluate moisture damage potential of asphalt concrete. IDT (Indirect Tensile Test) is one of the well known tests that have been designed to evaluate the fatigue and low temperature cracking potential of asphalt concrete. Piratheepan and his co-workers have tried to obtain the $c$ (cohesion) and $\varphi$ (internal friction angle) of asphalt concrete specimens using IDT test (Piratheepan et al. 2012). Birgisson and his co-workers have used IDT in their research to measure moisture damage potential of asphalt concrete (Birgisson et al. 2003). The energy based parameters obtained from materials' fracture mechanics have gained attention in assessing damage progress in asphalt concrete in recent years. Since there are few researches conducted on evaluation of moisture damage by these parameters, it is worth studying the energy based methods ability to predict the stripping potential of asphalt concrete. In the present study, IDT and resilient modulus tests were performed on the asphalt concrete samples considering the effect of the moisture conditioning, ageing and temperature. The energy based parameters such as fracture energy, elastic energy and dissipated creep strain energy obtained by IDT tests were used to evaluate the deleterious effects of moisture on asphalt concrete mechanical properties. During the research it was also attempted to derive new energy based parameters which were normalized by the specimens' failure strain in order to gain better predictors of moisture damage.

\section{Background}

IDT test has been widely used in two forms: destructive and non-destructive. The main application of nondestructive form of IDT is to obtain creep compliance, dynamic modulus and phase angle and to provide dynamic modulus master curves (Kim et al. 2002; Kim 2002; Momen 2004; Grant 2001). Destructive form of IDT test is chiefly used to evaluate the fatigue and low temperature cracking susceptibility of asphalt concrete (Das 2012; Marasteanu et al. 2004). In some researches, the destructive IDT has been used to study some other types of distresses such as moisture damage (Birgisson et al. 2003). Using the concept of fracture mechanics, Birgisson and his co-workers have attempted to find the effect of moisture damage on fracture mechanics of asphalt concrete (Birgisson et al. 2003). Performing this form of IDT can yield a stress-strain curve up to failure for each testing material. A stress-strain curve can be used to extract the parameters such as Fracture Energy (FE), Dissipated Creep Strain Energy (DCSE) and Elastic Energy (EE) as can be seen in Figure 1 (Grant 2001; Zhang et al. 2001). 


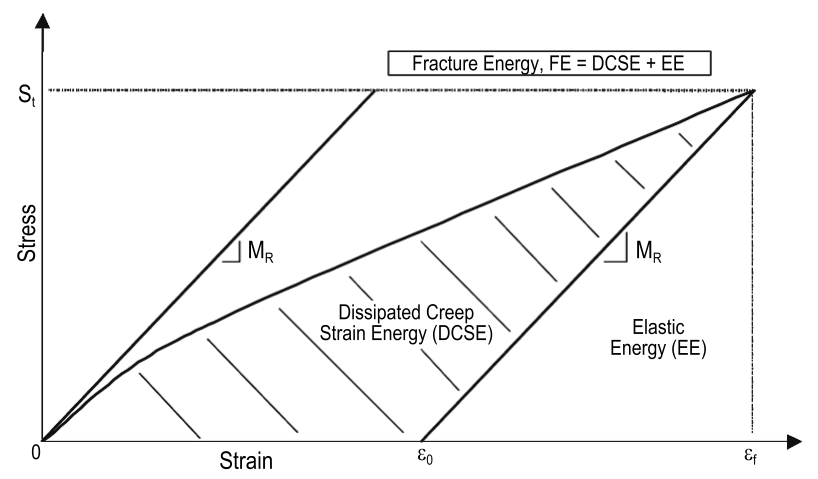

Fig. 1. Schematic of energy based parameters obtaining from a stress-strain curve after (Grant 2001; Zhang et al. 2001)

In accordance with the schematic diagram from Figure 1, tensile strength $\left(S_{t}\right)$, failure strain $\left(\varepsilon_{f}\right)$, permanent strain $\left(\varepsilon_{0}\right)$, and resilient modulus (MR) are the basic parameters that can be extracted from a stress-strain curve in order to calculate the mentioned energy based responses.

Birgisson and his co-workers and Roque and his co-workers defined the concept of DCSE threshold (Birgisson et al. 2003; Roque et al. 2002a). They measured the number of loading cycles required for the DCSE to reach its threshold, and a pre-existing crack propagates for a length of 1 inch. According to Birgisson et al. and some other researchers, taking DCSE into account has the advantage of considering the real behaviour of the asphalt concrete over a wide range of stresses including destructive and non-destructive stresses (Birgisson et al. 2003; Roque et al. 2002a). In Birgisson's et al. work, resilient modulus and Indirect Tensile Strength (ITS) tests were conducted to calculate the FE and DSCE. According to the definitions presented in previous studies, FE and DCSE show the sudden fracture and the growth of the micro-cracks threshold respectively (Zhang et al. 2001; Roque et al. 2002a, 2002b). Birgisson et al. (2003) believed that the parameters introduced above, can not only control the initiation and propagation of crack in asphalt concrete, but can also be effectively used to evaluate the detrimental effects of water.

Research conducted by Khalid and Monney is among other studies that have been conducted recently based on the concepts of fracture mechanics. In this research, fracture energy and fracture toughness of emulsified asphalt mixtures have been used as criteria for mixture moisture susceptibility (Khalid, Monney 2009). By integrating different parameters obtained from an experimental test such as IDT, multi-factor parameters which are believed to allow a more comprehensive evaluation of the moisture damage potential of asphalt concrete, can be attained (Caro et al. 2008). Although the energy concepts of adhesion have long been used in recognition of moisture susceptibility of asphalt-aggregate system (Cheng et al. 2002, 2003; Kanitpong, Bahia 2005), there seems to be fewer researches around the applicability of the energy based fracture responses to evaluate moisture damage of asphalt concrete. An attempt has been made here to look at this matter closely.

\section{Objectives and test procedures}

The main objective of the research is to investigate whether the energy based responses can distinguish the moisture sensitive and moisture resistant asphalt mixture under different environmental conditions. To this end, the IDT resilient modulus and strength tests have been conducted on asphalt concrete samples having different types of aggregates (granite and limestone). The tests, on the dry and moisture conditioned samples, were conducted at three temperatures of $4.4{ }^{\circ} \mathrm{C}, 21.1{ }^{\circ} \mathrm{C}$ and $37.8{ }^{\circ} \mathrm{C}$ (the same temperatures at which the dynamic modulus tests are recommended to be performed). Aging of the mixtures was also studied as another influencing factor on moisture sensitivity of asphalt concrete. Different energy based responses including FE, DCSE and EE were calculated for each specimen using the testing results. FE is the total energy that a material absorbs until it factures. This energy can be divided into two parts; the EE and the DCSE. The EE is the part of the total energy that is stored during the loading and can be released if the sample is unloaded. This energy corresponds to elastic strain. The DCSE is the irreversible part of the FE. This part of the energy, which corresponds to the permanent deformations, is consumed to create irreversible damage in the material. ANOVA (Analysis of Variance) tests were also performed on the obtained results to study the sensitivity of the responses to the testing parameters and to determine the most sensitive response to moisture effect.

\subsection{Sample preparation}

The aggregates used in samples preparation were of two types; granite and limestone. These types of aggregates are mostly used in local projects and can be representatives of hydrophilic and hydrophobic aggregates respectively. Figure 2 shows the chosen grading and its limits for mixture preparation. Tables 1 and 2 show the asphalt and aggregates properties.

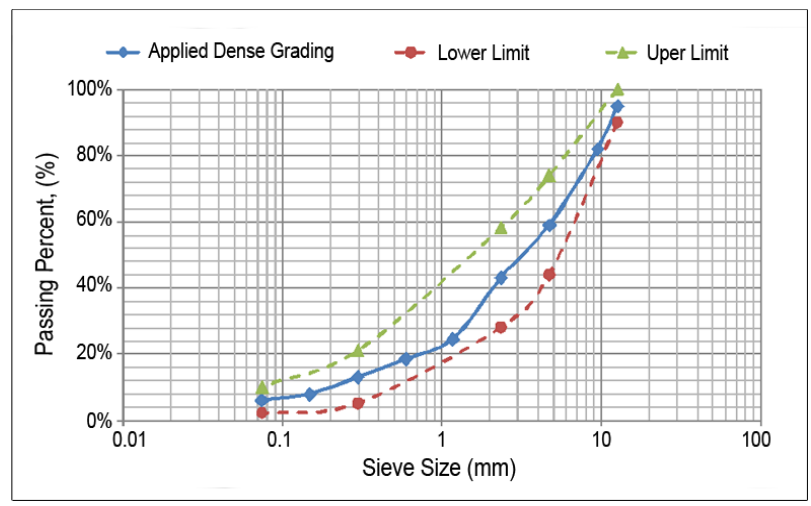

Fig. 2. Grading curve used for granite and limestone mixtures 
Table 1. Physical and mechanical properties of $60 / 70$ pen asphalt

\begin{tabular}{l|l|l}
\hline \multicolumn{1}{c|}{ Test } & \multicolumn{1}{c|}{ Standard Code } & Result \\
\hline $\begin{array}{l}\text { Ductility at } 25{ }^{\circ} \mathrm{C}(\mathrm{Cm}) \\
\begin{array}{l}\text { Penetration at } 25{ }^{\circ} \mathrm{C} \\
(\mathrm{mm})\end{array}\end{array}$ & $\begin{array}{l}\text { ASTM D113-07 (2007) } \\
(2013)\end{array}$ & 100 \\
$\begin{array}{l}\text { Softening point }\left({ }^{\circ} \mathrm{C}\right) \\
\begin{array}{l}\text { Specific gravity at } 25{ }^{\circ} \mathrm{C} \\
\left(\mathrm{gr} / \mathrm{Cm}^{3}\right)\end{array}\end{array}$ & ASTM D36-06 (2006) & 50.1 \\
\hline
\end{tabular}

Before preparing the test specimens, Marshall method (ASTM D1559-89 1998) was used to obtain the optimum asphalt content for each type of aggregate. Based on the calculations, the optimum asphalt content was determined as $4.8 \%$ for limestone aggregate mixtures and $6.2 \%$ for granite aggregate mixtures. Although the binder content has an influence on the moisture susceptibility of the mixtures, it has no effect on the evaluation of the applicability of the energy based parameters as reported herein. The binder content variation in mixtures was therefore eliminated by averaging the optimum asphalt amounts for two different aggregate types and the test specimens were made with $5.5 \%$ of $60 / 70$ Pen asphalt. Using binder content more that optimum amount for limestone mixtures may help them to better resist the moisture damage and in contrast fabricating the granite mixtures with binder content less than the optimum amount is expected to make them more moisture susceptible. For this reason, it was not intended to compare the limestone and granite mixtures moisture susceptibility in the present work. Testing samples were fabricated by a compactor in cuboid shape with the dimensions of $15 \times 17 \times 45 \mathrm{~cm}$. The compactor is designed to exert static force in a vertical direction and cyclic shear forces in lateral direction to the loose mixtures inside the mould until the sample reaches a predefined air void or bulk density amount. The shearing action of the compactor is devised to closely replicate the condition under which the asphalt mixture is placed in the field. Figure 3 presents a picture of the compactor.

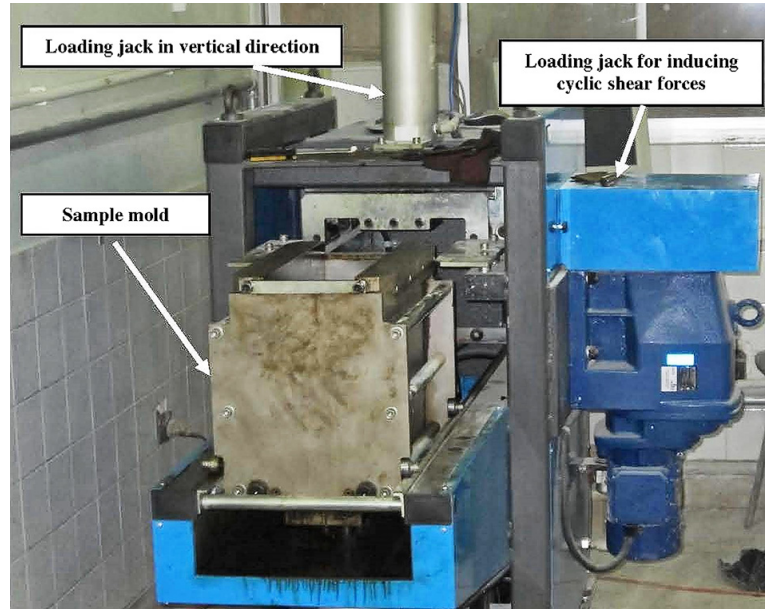

Fig. 3. PresBox compactor

All slabs were compacted to the target air void content of 7\%. In order to ascertain that the cuboids are compacted to the constant level of air void, all mixtures were compacted at $140{ }^{\circ} \mathrm{C}$ and with the application of $100 \mathrm{kPa}$ vertical stress for $15-20$ cycles. The samples for IDT testing with $142 \mathrm{~mm}$ diameter and $38 \mathrm{~mm}$ thickness were then cored and cut from the fabricated slabs. The final air void of the cored cut samples were $7 \pm 0.5 \%$ according to ASTM D2041/D2041M-11 (2011) and ASTM D2726/ D2726M-14 (2014). In order to simulate the long term aging effect on mixtures, part of the fabricated disc-shape specimens were kept in an oven at $85{ }^{\circ} \mathrm{C}$ for $120 \mathrm{hr}$ according to AASHTO R 30-02 (2010). It is believed that this process of aging corresponds to 5 to 7 years of aging in field condition (Singh et al. 2011).

To evaluate the effects of moisture on specimens' behaviour, they were divided into two groups. Specimens of the first group were tested in dry condition and the specimens of the other group were tested after going through the moisture conditioning process. In order to moisture condition the specimens; they were saturated inside a vacuum desiccator filled with water according to ASTM D4867/D4867M-09 (2009). The vacuum of $525 \mathrm{mmHg}$

Table 2. Physical and mechanical properties of aggregates

\begin{tabular}{l|l|l|l}
\hline \multicolumn{1}{c|}{ Test } & \multicolumn{1}{c}{ Standard code } & \multicolumn{2}{c}{ Limestone } \\
\cline { 2 - 4 } & \multicolumn{1}{|c}{ Granite } \\
\hline LA Abrasion loss (\%) & AASHTO T096-02-UL (2006) & 20.5 & 19 \\
Crushed in one face (\%) & ASTM D5821-13 (2013) & 98 & 100 \\
Crushed in two face (\%) & ASTM D5821-13 (2013) & 98 & 93 \\
Coating of aggregate (\%) & AASHTO T182-84-UL (2002) & $>95$ & $>95$ \\
Flakiness (\%) & BS 812 (1975) & 6 & 20 \\
Sand equivalent (\%) & AASHTO T176-08-UL (2008) & 75 & 75 \\
Sodium sulphate soundness (\%) & AASHTO T104-99-UL (2007) & Fine aggregates $=1.8$ & Fine aggregates $=2.9$ \\
\hline
\end{tabular}


was applied to the desiccator for $10 \pm 2 \mathrm{~min}$. The saturation time was chosen so that all of the specimens reach a saturation level of $65 \pm 3 \%$. Saturated samples were placed inside a freezer kept at $-18{ }^{\circ} \mathrm{C}$ for $15 \mathrm{hrs}$ and then placed in a $60{ }^{\circ} \mathrm{C}$ water bath for $24 \mathrm{hrs}$.

\subsection{Testing method}

During the research, two sets of tests were conducted (resilient modulus and IDT strength). Different combinations of testing parameters considered during the research are given in Table 3. Tests were performed with three replicates for each combination of the testing parameters. In order to derive valid results from the tests, a general full factorial experimental design was applied to the test parameters using Minitab software before performing the test program. Since the behavioural nature of the granite and limestone aggregates was different, a separate factorial design was chosen for each aggregate type. By using this designing method and considering three replicates for each set of test parameters $36(2 \times 2 \times 3 \times 3)$ tests were conducted for each aggregate type.

The IDT resilient modulus tests were performed by applying a repeated haversine waveform load to the samples. The loading wave width was 0.1 second and it was followed by a 0.9 second rest period in each cycle. During the resilient modulus test, the load was chosen to ensure that the horizontal strain remains almost under $150 \mu$ s. Figure 4 shows a sample of loading and the recorded strains in the resilient modulus test. For each specimen, 10 pulses of load were applied (5 pulses for preconditioning and 5 pulses for modulus calculation). In each pulse, the ratio of the maximum stress to maximum recoverable strain was calculated as the resilient modulus

Table 3. Test parameters used in indirect strength and resilient modulus test

\begin{tabular}{l|l|l|l}
\hline $\begin{array}{l}\text { Aggregate } \\
\text { type }\end{array}$ & $\begin{array}{l}\text { Aging } \\
\text { condition }\end{array}$ & $\begin{array}{l}\text { Moisture } \\
\text { conditioning }\end{array}$ & $\begin{array}{l}\text { Temperature } \\
\left({ }^{\circ} \mathrm{C}\right)\end{array}$ \\
\hline Limestone & un-aged, aged & dry, wet & $4.4,21.1,37.8$ \\
\hline Granite & un-aged, aged & dry, wet & $4.4,21.1,37.8$ \\
\hline
\end{tabular}

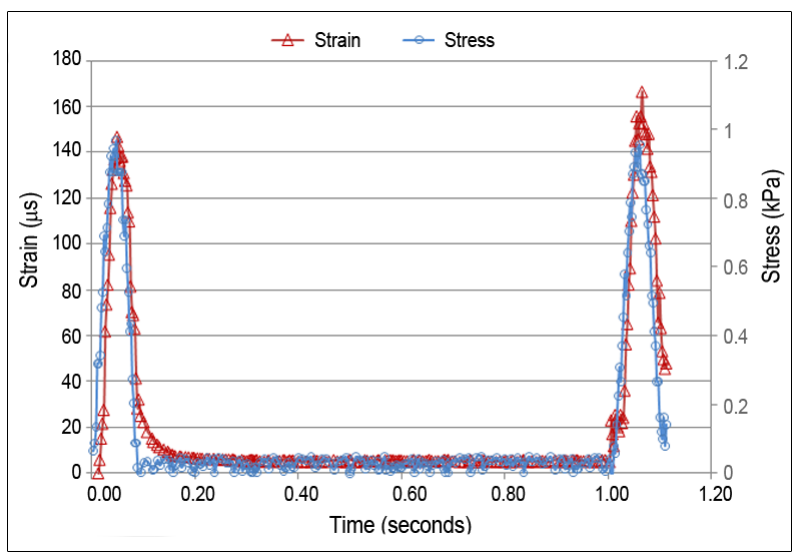

Fig. 4. A sample loading pulse in resilient modulus test of that pulse. Then the average of the obtained amounts for the last 5 pulses was reported as the resilient modulus of the specimen.

The IDT strength test, as prescribed in ASHTTO TP9-96 (1996), is performed by applying a monotonic load increasing with a rate of $12.5 \mathrm{~mm}$ per minute to the disc shaped samples $(142 \mathrm{~mm}$ diameter and $38 \mathrm{~mm}$ thickness). As mentioned previously, after obtaining the resilient modulus of samples, stress-strain curves can be used to extract valuable data such as elastic energy, dissipated creep strain energy, fracture energy, and etc. In the present work, the mentioned parameters were calculated based on the area under stress-strain curve using Simpson's method according to Eqn (1):

$$
S_{\text {area }}=\frac{1}{2}\left[\sum_{i=1}^{n} x_{i} y_{i+1}-\sum_{i=1}^{n} x_{i+1} y_{i}\right],
$$

where: $x_{i}-$ the $i^{\text {th }}$ strain component of the stress-strain curve points; $y_{i}-$ the $i^{\text {th }}$ stress component of the stressstrain curve points.

\section{Results analysis}

\subsection{Experimental energy based results}

In this work, tests for each set of variants were conducted with three replicates. The details of testing methods for both resilient modulus and strength tests were explained in the previous section. The resilient modulus of specimens was calculated by averaging the stress to strain ratio for five pulses of loading in each sample and the average amount for three replicates were reported as the resilient modulus of the given testing condition. In the IDT strength tests, the average of the extracted responses (FE, EE, DCSE) for the replicates were reported as the energy responses for each combination of testing parameters. Figure 5 illustrates the resilient modulus results and Figures 6 to 8 show the amounts of the three energy based parameters for different testing conditions. The \pm 2 times of standard error which corresponds to the $95 \%$ confidence level is shown in each figure. The error bars show the repeatability of the replicates in each test.

In Figures $5 \mathrm{a}$ and $5 \mathrm{~b}$ the resilient modulus of limestone mixtures can be found. According to the graphs there is no remarkable difference between the modulus of wet and dry samples at neither of the testing temperatures. The limestone mixtures' moduli did not change even after aging. The resilient modulus of granite mixtures are shown in Figures $5 \mathrm{c}$ and $5 \mathrm{~d}$. As can be realized from the figures, moisture conditioning the specimens has considerably decreased their resilient modulus. According to the figure, the aging process has caused an increase in the stiffness of the samples. Results of some other researches (Zegeye et al. 2012; Jeremiah et al. 2013) indicate higher stiffness for aged specimens compared to un-aged samples in IDT testing method that supports our findings here. The granite samples (both aged and unaged) have experienced severe moisture damage as the 


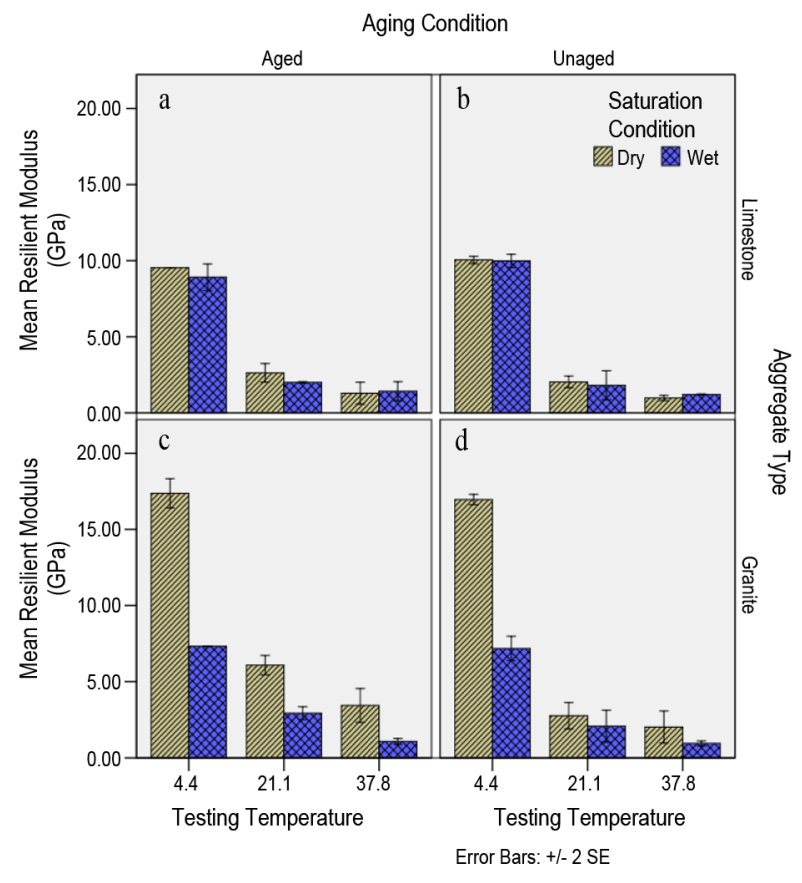

Fig. 5. Resilient modulus of: a) limestone aged mixtures; b) limestone un-aged mixtures; c) granite aged mixtures; d) granite un-aged mixtures

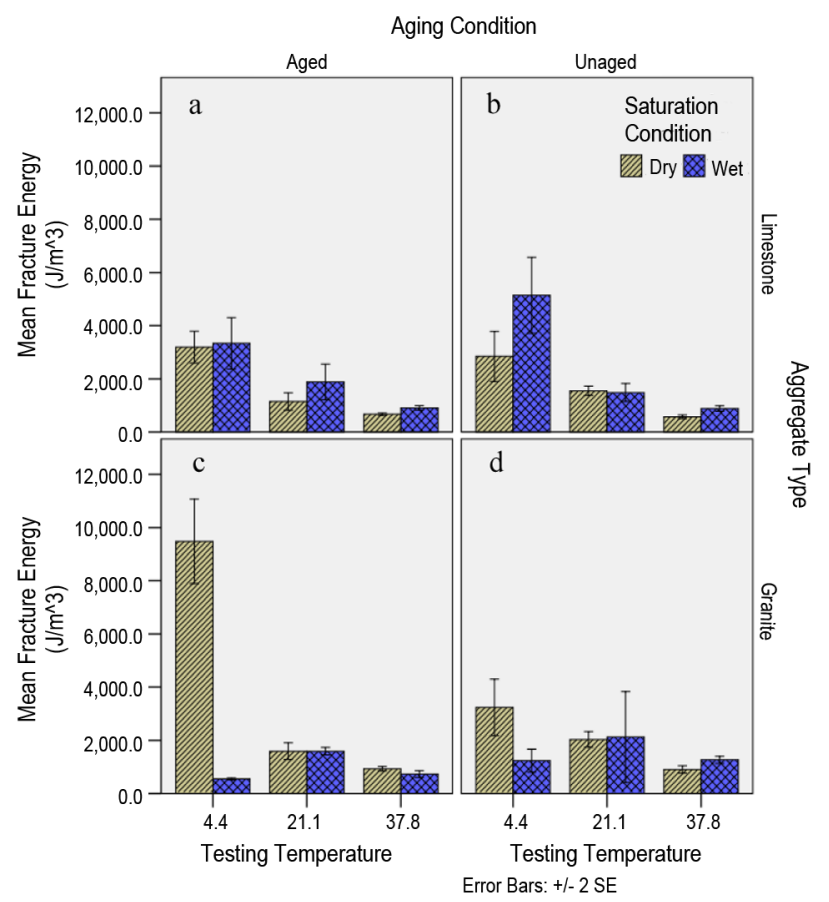

Fig. 6. Fracture energy of: a) limestone aged mixtures; b) limestone un-aged mixtures; c) granite aged mixtures; d) granite un-aged mixtures

difference between the resilient modulus of dry and wet samples is considerable.

Figure 6 shows the calculated fracture energy for each testing condition. For mixtures with limestone aggregates, the fracture energy increased after moisture conditioning. This was the case for both un-aged and

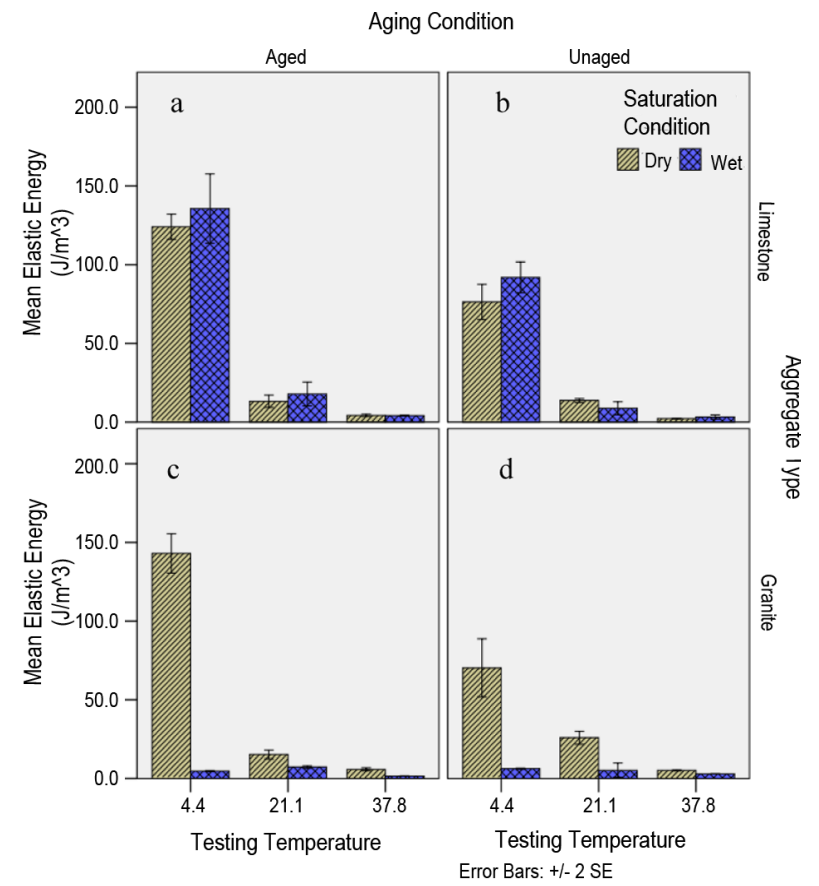

Fig. 7. Elastic energy of: a) limestone aged mixtures;

b) limestone un-aged mixtures; c) granite aged mixtures;

d) granite un-aged mixtures

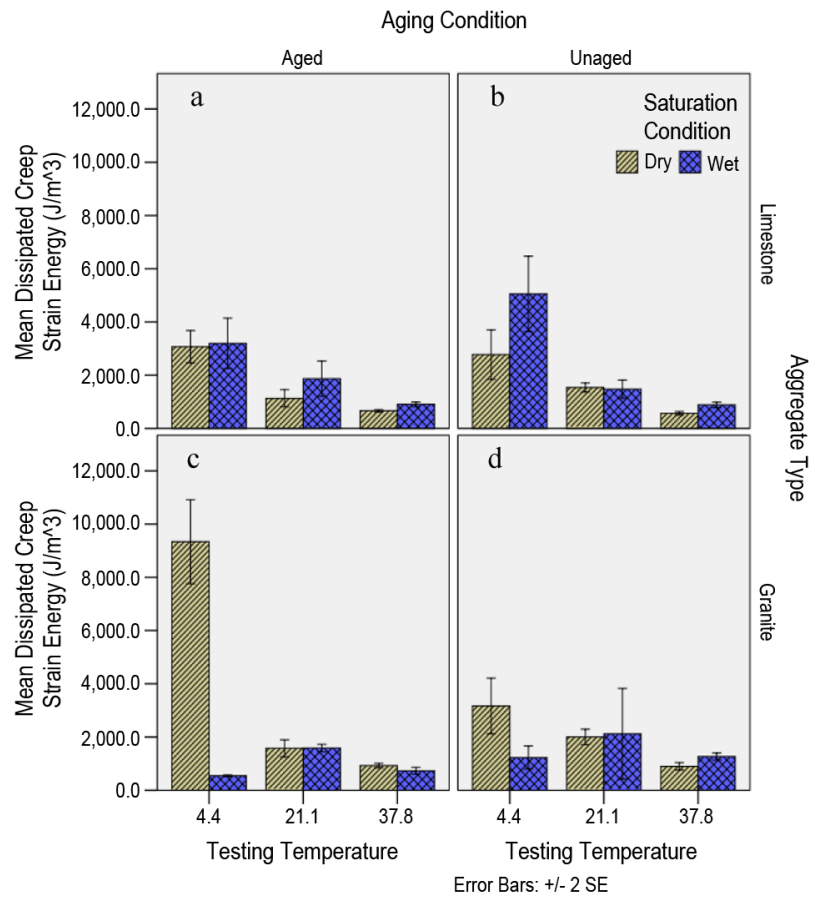

Fig. 8. Dissipated creep energy of: a) limestone aged mixtures; b) limestone un-aged mixtures; c) granite aged mixtures; d) granite un-aged mixtures

aged specimens. In granite mixtures, the fracture energy of moisture conditioned mixtures was considerably lower than that of dry mixtures at testing temperature of $4.4^{\circ} \mathrm{C}$, but at higher temperatures, moisturizing did not affect the fracture energy. Aging process results in stiffer asphalt concrete. The increase in fracture energy due to aging 
may not be generally accepted; however, there are evidences that in some type of mixtures, long term aging can raise the cohesion work which produces a specimen with larger fracture energy (Howson et al. 2007). The moisture conditioning process may also increase the failure strain of specimens as will be discussed later. Because of the presented explanations, fracture energy of specimens might give some ambiguous results in moisture damage evaluation of asphalt concrete, particularly when the difference of moisture conditioned and dry specimens are marginal (for example in limestone mixtures here).

In Figure 7 the elastic energy is presented for different mixtures. In the specimens made of limestone (Figs $7 \mathrm{a}$ and $7 \mathrm{~b}$ ) the elastic energy of wet samples were larger than that of dry samples. Mixtures made of granite aggregates experience a considerable difference in their elastic energy storage potential when exposed to moisture damage (Figs 7c and 7d). The graph also testifies that aging process aggravates the effects of moisture damage at lower temperature $\left(4.4^{\circ} \mathrm{C}\right)$. At this temperature, the average elastic energy for un-aged specimens experienced almost $60 \mathrm{~J} / \mathrm{m}^{3}$ decrease after moisture conditioning while the aged specimens went through an average decrease of $140 \mathrm{~J} / \mathrm{m}^{3}$ after moisture conditioning.

DCSE parameter, which was calculated by subtracting elastic energy from fracture energy, is provided in Figure 8. The obtained DCSE for different specimens obeys the same pattern as their FE. Limestone mixtures experienced an increase in their DCSE after moisture conditioning. In granite mixtures, the DCSE decreased at $4.4{ }^{\circ} \mathrm{C}$, however, the moisturizing did not have a sensible effect on the parameters at higher temperatures $\left(21.1^{\circ} \mathrm{C}, 37.8^{\circ} \mathrm{C}\right)$.

\subsection{Statistical analysis of experimental results}

A complete and valid evaluation of responses reported earlier, entails knowing how sensitive the responses are to changes in testing parameters using statistical methods. In order to consider the significance of the effect of each factor on the responses, the ANOVA was performed on all of the affecting factors using Minitab software release 15.1.30.0 (2007). In ANOVA analysis $F$ and $P$ tests were utilized to see if there was a strong correlation between the responses and the testing parameters. Since the behaviour of limestone and granite specimens were quite different the data was grouped based on the type of aggregates. ANOVA was therefore applied on three energy base responses (FE, EE, DCSE) on grounds of the separate full factorial design for each aggregate type. Table 4 presents the ANOVA results. According to this table, testing temperature is the most influential factor on all of the responses as the significance tests give quite a large $\mathrm{F}$ values for temperature factor in all of the responses and the corresponding $\mathrm{P}$ values are smaller than 0.1. Elastic energy of limestone specimens is also influenced by aging factor while it was almost ineffective on the other two responses (FE, DCSE). Statistical analysis indicate that moisture conditioning the limestone specimens wouldn't cause a sensible change in their EE $(\mathrm{P}>0.1)$; however, FE and DCSE seem to have a strong dependency on moisture conditioning. This dependency may not be relied on as the moisture susceptibility of limestone mixtures because of three reasons. Firstly, the moisture conditioned limestone specimens have higher FE and DCSE than dry samples according to Figures 6, 8. Secondly, it is generally believed that mixtures made with limestone aggregates have high resistance to moisture damage (Kim 2009). Thirdly, the limestone mixtures tested in this work, were fabricated with binder content higher than their optimum binder amount which might make them even less prone to moisture damage. ANOVA for granite mixtures are also provided in Table 4. The first thing that draws ones attention is that the aging does not influence the responses (FE, EE, DCSE) as much as the other two parameters (moisture conditioning and temperature). This finding is in agreement with the testing results illustrated by Figures 6 to 8. According to Table 4, all three energy based responses are sensitive either to moisture conditioning or to temperature change ( $\mathrm{P}$ value of smaller than 0.1 ) in granite mixtures here. Among the responses, the EE has a stronger correlation with the moisture conditioning and temperature parameters.

\subsection{Comparison of statistical analysis with testing results}

The main idea of the present research was to investigate whether the energy based responses could be used for evaluating the stripping potential of asphalt concrete. The experimental analysis thus far shows that FE, DCSE and $\mathrm{EE}$ of limestone mixtures mainly increase or remain almost unchanged after moisture conditioning. Based on this analysis, granite mixtures experience a considerable decrease in their energy parameters at $4.4{ }^{\circ} \mathrm{C}$ and a negligible decrease in those parameters at higher temperatures. On the other hand, the statistical analysis shows that in both types of aggregates, the moisture conditioning is an effective factor on energy based responses. The question is whether the introduced parameters can identify the mixtures with stripping potential and whether this can be endorsed by the statistical analysis? To find the answer to this question, and to gain a better insight into the obtained results, a limited number of the pictures of the tested specimens are provided as examples. According to the observations, limestone samples (either wet or dry), when tested at $4.4{ }^{\circ} \mathrm{C}$, failed due to aggregate fracture and binder cohesion failure. No sign of adhesive failure was detected in these specimens. Examples of broken limestone specimens are shown in Figures 9a and 9b. By increasing the temperature, failure mode changed such that at $21.1{ }^{\circ} \mathrm{C}$, a blend of cohesive and adhesive failure was detected in the tested specimens. In limestone specimens tested at $21.1{ }^{\circ} \mathrm{C}$, the amount of aggregate fracture was considerably lower than that in specimens tested at $4.4{ }^{\circ} \mathrm{C}$. Figures $9 \mathrm{c}$ and $9 \mathrm{~d}$ show sample pictures of the limestone specimens tested at $21.1^{\circ} \mathrm{C}$. 
Table 4. Results of ANOVA test on sensitivity of different responses to independent factors

\begin{tabular}{|c|c|c|c|c|c|c|c|}
\hline Mixture type & Dependent variable & Independent variable & DF & Sum of square & Mean square & $\mathrm{F}$ & $\mathrm{P}$ \\
\hline \multirow{11}{*}{ Limestone } & \multirow{4}{*}{$\mathrm{FE}$} & Aging Condition & 1 & 456859 & 456859 & 0.990 & 0.326 \\
\hline & & Testing Temperature & 2 & 53100934 & 26550467 & 57.820 & 0.000 \\
\hline & & Saturation Condition & 1 & 3348647 & 3348647 & 7.290 & 0.011 \\
\hline & & Error & 31 & 14234967 & 459192 & & \\
\hline & \multirow{5}{*}{$\mathrm{EE}$} & Aging Condition & 1 & 2648 & 2648 & 15.120 & 0.000 \\
\hline & & Testing Temperature & 2 & 78363 & 39181 & 223.810 & 0.000 \\
\hline & & Saturation Condition & 1 & 192 & 192 & 1.090 & 0.304 \\
\hline & & Error & 31 & 5427 & 175 & & \\
\hline & & Aging Condition & 1 & 529063 & 529063 & 1.160 & 0.290 \\
\hline & \multirow{2}{*}{ DCSE } & Testing Temperature & 2 & 49158490 & 24579245 & 53.840 & 0.000 \\
\hline & & $\begin{array}{l}\text { Saturation Condition } \\
\text { Error }\end{array}$ & $\begin{array}{l}1 \\
31 \\
\end{array}$ & \begin{tabular}{|l|}
3298182 \\
14152001 \\
\end{tabular} & $\begin{array}{l}3298182 \\
456516 \\
\end{array}$ & 7.220 & 0.011 \\
\hline \multirow{12}{*}{ Granite } & \multirow{4}{*}{ FE } & Aging Condition & 1 & 4148916 & 4148916 & 1.010 & 0.324 \\
\hline & & Testing Temperature & 2 & 44337764 & 22168882 & 5.370 & 0.010 \\
\hline & & Saturation Condition & 1 & 28497845 & 28497845 & 6.910 & 0.013 \\
\hline & & Error & 31 & $1.28 \mathrm{E}+08$ & 4127022 & & \\
\hline & \multirow{4}{*}{$\mathrm{EE}$} & Aging Condition & 1 & 958.2 & 958.2 & 1.180 & 0.286 \\
\hline & & Testing Temperature & 2 & 18573.8 & 9286.9 & 11.410 & 0.000 \\
\hline & & Saturation Condition & 1 & 14088.4 & 14088.4 & 17.310 & 0.000 \\
\hline & & Error & 31 & 25236.1 & 814.1 & & \\
\hline & \multirow{4}{*}{ DCSE } & Aging Condition & 1 & 4023770 & 4023770 & 1.000 & 0.325 \\
\hline & & Testing Temperature & 2 & 42563468 & 21281734 & 5.300 & 0.010 \\
\hline & & Saturation Condition & 1 & 27244669 & 27244669 & 6.780 & 0.014 \\
\hline & & Error & 31 & $1.25 \mathrm{E}+08$ & 4016831 & & \\
\hline
\end{tabular}

Figure 10 shows the example pictures of the split samples of granite mixtures. The distinguishing effects of moisture damage can be found in specimens tested at $4.4{ }^{\circ} \mathrm{C}$ as may be seen in Figures 10a and 10b. The specimen shown in Figure 10a was tested in dry condition. It is obvious that most aggregates are broken and the adhesive bond of the asphalt to aggregate has not been damaged; however, the moisture conditioned specimen with the same volumetric properties experienced severe stripping as the mastic has been stripped off most of the aggregates (see Fig. 10b as an example). Granite dry specimens when tested at $21.1{ }^{\circ} \mathrm{C}$, mostly went through cohesive failure (Fig. 10c), however their failure mode changed when the specimens were tested after moisture conditioning. In the latter condition, both cohesive and adhesive failure contributed to the specimens' failure (Fig. 10d). According to the reports that have been presented by several previous researchers (Bagampadde et al. 2013; Kanitpong, Bahia 2005; Kim, Coree 2005; Alam et al. 1998; Cheng et al. 2003), granite mixtures are more prone to moisture damage than limestone mixtures. However, the poor performance of moisture conditioned granite mixtures in this research could not be only due to their moisture sensitive nature but also due to the fact that they have been prepared by binder content lower than the optimum amount. This, for sure, can decrease the binder film thickness around the aggregates and increase the probability of adhesive damage after moisture conditioning (Birgisson et al. 2003; Moraes et al. 2011).
It should be emphasize that, for the sake of brevity, only limited instances of the visual observations are provided here. According to the observations it can be said that the aged limestone specimens tested at $4.4{ }^{\circ} \mathrm{C}$ during the research, showed no sign of adhesive failure. In most of these specimens tested in IDT form, the crack line went through the aggregates. Limestone aged specimens when tested in dry condition at $21.1{ }^{\circ} \mathrm{C}$, mostly experienced cohesive failure. Visual inspection of the broken specimens of the mentioned type showed that aggregates and the bond between the aggregates and the mastic remained intact after the specimens were broken. Aged limestone mixtures tested at $21.1{ }^{\circ} \mathrm{C}$ after moisture conditioning almost showed similar behaviour to the aged dry limestone specimens; however a little adhesive failure was detected in the specimens because of moisture conditioning. The results of visual observations on the aged limestone mixtures indicated that these mixtures were not moisture susceptible, because either at low or at high temperatures there did not seem to be a serious difference between the failure mode of dry and wet samples. This can be because of the hydrophobic nature of limestone and also because the fact that these mixtures have been prepared with the binder content more that the optimum binder amount.

Aged granite specimens were also investigated for their failure mode. In dry aged granite samples tested at $4.4{ }^{\circ} \mathrm{C}$, the crack went through the mastic. Same type of mixtures showed drastic symptoms of stripping after 

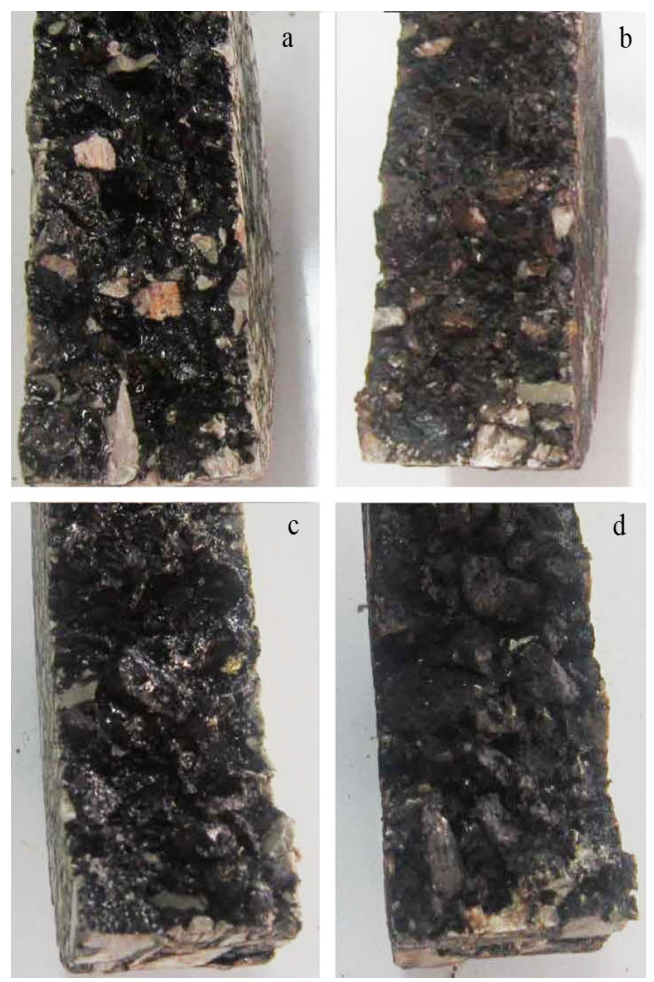

Fig. 9. Broken faces of the split samples: a) for dry limestone sample at $4.4^{\circ} \mathrm{C}$; b) for moisture conditioned limestone sample at $4.4{ }^{\circ} \mathrm{C}$; c) for dry limestone sample at $21.1{ }^{\circ} \mathrm{C}$; d) for moisture conditioned limestone sample at $21.1{ }^{\circ} \mathrm{C}$

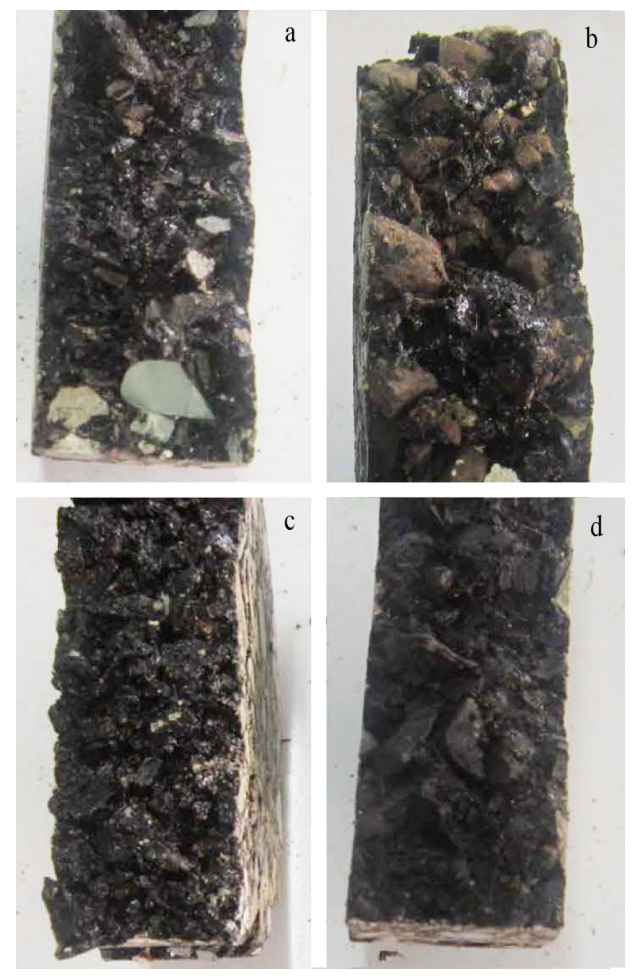

Fig. 10. Broken faces of the split samples: a) for dry granite sample at $4.4^{\circ} \mathrm{C}$; b) for moisture conditioned granite sample at $4.4{ }^{\circ} \mathrm{C}$; c) for dry granite sample at $21.1^{\circ} \mathrm{C}$; d) for moisture conditioned granite sample at $21.1^{\circ} \mathrm{C}$ moisture conditioning. Increasing the testing temperature from $4.4^{\circ} \mathrm{C}$ to $21.1^{\circ} \mathrm{C}$ in granite mixtures, made only a slight difference in their failure mode. Dry samples mostly show cohesive failure and wet samples mostly show adhesive failure. It can be said that the granite specimens tested in this work, are greatly moisture susceptible both before and after aging; however, aging might make them a little more moisture susceptible.

Defining a parameter that can be used as an index of stripping potential of asphalt mixtures requires evidences of the samples behaviour. Although statistical analysis of the test results (Table 4) indicted that moisture conditioning was an effective factor on FE and DCSE of the limestone samples, visual inspections of the tested samples, which were briefly discussed, along with the testing results, showed that limestone mixtures tested in this work were not moisture susceptible as the moisture conditioning process had increased the FE and DCSE of these samples (Figs 6a, b, 8a, b). Figures $6 \mathrm{~d}$ and $8 \mathrm{~d}$ also show that moisture conditioning have increased the FE and DCSE of granite samples at high temperatures, while visual inspections of these specimens detected moisture damage in them even at high temperatures. Due to these inconsistencies, it might be concluded that deciding about the specimens> moisture or temperature sensitivity using merely the statistical analysis of the introduced responses, does not suffice. It is also realized that factors such as FE, DCSE and etc. may not show the samples real behaviour, but it may be asked why?

Failure strain results of tested specimens have been illustrated in Figure 11. Two important points can be realized from the graph. Firstly, the failure strain increased as the testing temperature went higher. Secondly, the failure deformation of moisturized samples was way more than that of dry samples in most testing conditions. The increase in testing temperature also caused an increase in the difference between wet and dry samples failure strain. Based on Figure 11, it can be concluded that moisture damaged samples are more deformable than dry specimens even though their indirect strength is lower than dry specimens. According to failure deformation graph, the aged specimens failed after lower strain application compared to un-aged specimens. This could be because of the brittle nature of the aged samples (Baek et al. 2012; Alshamsi 2006).

To make a clearer explanation, two stress-strain schematics have been provided in Figure 12. It has been defined in previous sections that FE is the area under the stress-strain curve so the stress and the strain are the two main components of the FE response. A stressstrain curve for an intact specimen at lower temperature is shown in Figure 12a. It can be realized that the failure strain of the material is low whereas its strength is quite high. On the other hand, Figure 12b shows the behaviour of either a moisture damaged specimen or a specimen at higher temperature (as it was seen before, both conditions can make the asphalt concrete fail after higher deforma- 


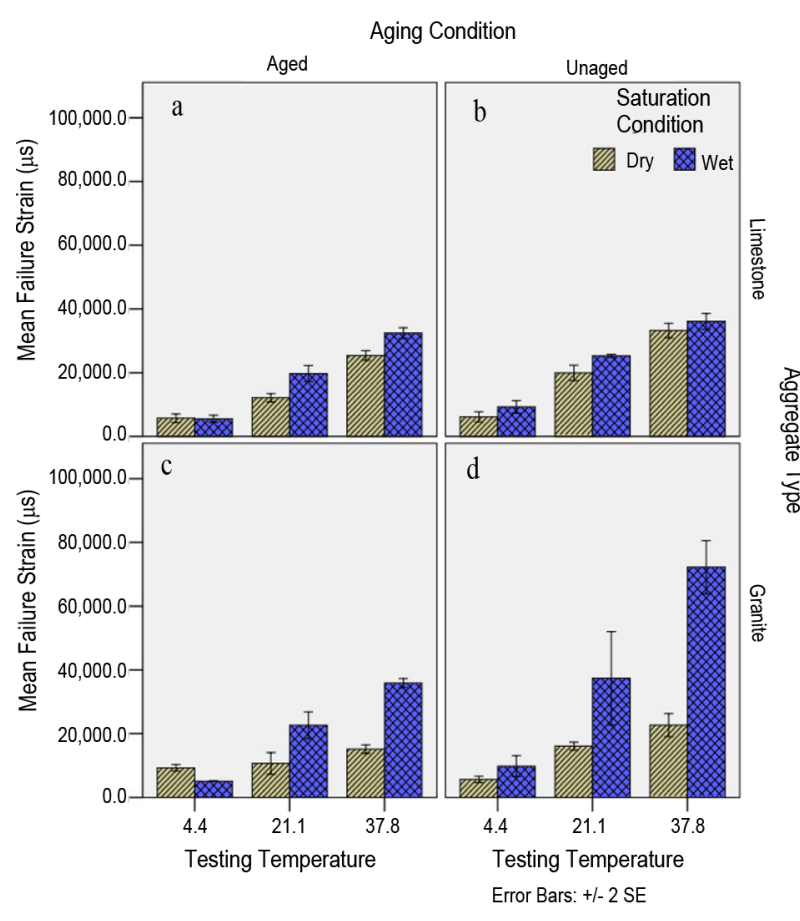

Fig. 11. Failure strain of: a) limestone aged mixtures;

b) limestone un-aged mixtures; c) granite aged mixtures;

d) granite un-aged mixtures

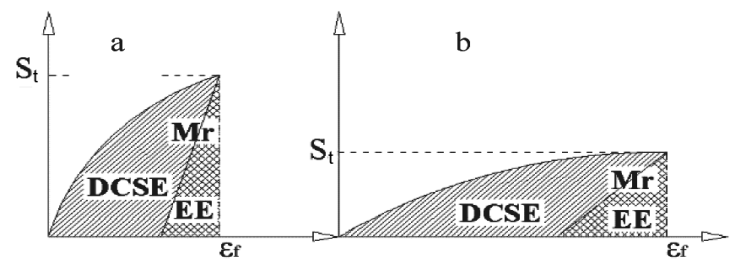

Fig. 12. Schematic of two stress-strain curves for: a) hard material; b) soft material

tions (Fig. 11). The schematics shown in Figures 12a and $12 \mathrm{~b}$ can have the same FE, since the lower component in each may be compensated with the other higher component. The same scenario holds true for the other energy based parameters such as DCSE, EE. Two specimens having different resilient modulus could have almost the same elastic energy. Moisture damaged specimen and an unconditioned specimen with the same volumetric properties may have almost the same FE, DCSE or EE, because in moisture conditioned samples the decrease in load bearing capacity is somewhat compensated with the increase in failure deformation; therefore, the FE of wet samples might stay constant or even take higher amounts compared to that of dry samples. This was the case particularly in limestone or granite mixtures tested at higher temperatures.

\subsection{Defining a modified energy based parameter}

To overcome the inconvenience of the conventional energy based parameters in moisture damage evaluation it was decided to eliminate the confusing effect of samples deformation by normalizing the energy based responses by the failure strain of the specimens. The fracture energy, elastic energy and dissipated creep strain energy that were normalized by failure strain are shown in Table 5 by NFE, NEE and NDCSE respectively, for different granite and limestone specimens (the amounts in Table 5 show the average of three replicates for each combination of test parameters). Using this method makes it possible to obtain a new meaningful parameter which indicates the average energy consumption of the specimen per unit strain. In other words, the amount of average energy that a sample takes per $1 \mu$ s from the start of the loading right up to its failure time is the normalized parameter. When a specimen takes more energy to go through a deformation corresponding to $1 \mu \mathrm{s}$, it can be said that the specimen is more resistant to damage in a given testing condition. In Table 5, the mixture type and the testing conditions have been shown with brief coding method. In this table, "D" stands for dry, "W", stands for wet, "U", stands for un-

Table 5. Normalized energy based parameters for different specimens and testing conditions

\begin{tabular}{l|l|l|l}
\hline $\begin{array}{l}\text { Testing } \\
\text { condition }\end{array}$ & $\begin{array}{l}\mathrm{NFE} \\
\left(\mathrm{mJ} / \mathrm{m}^{3} / \mu \mathrm{s}\right)\end{array}$ & $\begin{array}{l}\mathrm{NEE} \\
\left(\mathrm{mJ}^{\mathrm{m}} \mathrm{m}^{3} / \mu \mathrm{s}\right)\end{array}$ & $\begin{array}{l}\mathrm{NDCSE} \\
\left(\mathrm{mJ} / \mathrm{m}^{3} / \mu \mathrm{s}\right)\end{array}$ \\
\hline DUL-4.4 & 457.84 & 12.56 & 445.28 \\
WUL-4.4 & 551.83 & 10.04 & 541.79 \\
DAL-4.4 & 561.96 & 22.50 & 539.46 \\
WAL-4.4 & 597.26 & 24.62 & 572.64 \\
DUL-21.1 & 77.88 & 0.69 & 77.19 \\
WUL-21.1 & 58.65 & 0.34 & 58.31 \\
DAL-21.1 & 93.63 & 1.07 & 92.55 \\
WAL-21.1 & 94.25 & 0.88 & 93.37 \\
DUL-37.8 & 17.37 & 0.06 & 17.30 \\
WUL-37.8 & 25.02 & 0.09 & 24.93 \\
DAL-37.8 & 26.57 & 0.17 & 26.40 \\
WAL-37.8 & 28.14 & 0.12 & 28.02 \\
\hline DUG-4.4 & 567.07 & 12.37 & 554.70 \\
WUG-4.4 & 125.39 & 0.68 & 124.71 \\
DAG-4.4 & 1018.20 & 15.43 & 1002.77 \\
WAG-4.4 & 107.75 & 0.93 & 106.82 \\
DUG-21.1 & 126.07 & 1.60 & 124.46 \\
WUG-21.1 & 51.68 & 0.12 & 51.56 \\
DAG-21.1 & 151.85 & 1.54 & 150.31 \\
WAG-21.1 & 71.06 & 0.32 & 70.74 \\
DUG-37.8 & 39.83 & 0.23 & 39.60 \\
WUG-37.8 & 17.56 & 0.04 & 17.52 \\
DAG-37.8 & 61.52 & 0.38 & 61.14 \\
WAG-37.8 & 20.46 & 0.04 & 20.42 \\
\hline & & & \\
\hline
\end{tabular}


aged, "A", stands for aged, "L" stands for limestone, and "G", stands for granite. Therefore, dry aged limestone specimen that was tested at $4.4^{\circ} \mathrm{C}$ for instance, has been indicated with DAL-4.4.

To help a better understanding of the new defined responses, take the DAL-21.1 and WAL-21.1 as examples. The average amount of fracture energy consumption per unit strain is equal to $93.63\left(\mathrm{~mJ} / \mathrm{m}^{3} / \mu \mathrm{s}\right)$ and $94.25(\mathrm{~mJ} /$ $\mathrm{m}^{3} / \mu \mathrm{s}$ ) for DAL-21.1 and WAL21.1 respectively. This can indicate that moisturized aged limestone specimens take almost the same fracture energy to go through $1 \mathrm{mi}-$ cro strain comparing to dry aged limestone specimens. When dealing with granite mixtures, based on the Table 5 , it can be seen that DUG-4.4 specimen takes the fracture energy of $567.07\left(\mathrm{~mJ} / \mathrm{m}^{3} / \mu \mathrm{s}\right)$ while the WUG-4.4 specimen (moisturized samples with the same volumetric properties) takes less than one-fifth of that amount. Comparing the new defined parameters (normalized energy parameters) with the previous energy based parameters reveals that the normalized parameters are more in agreement with the visual observations of the tested specimens. For instance, in limestone mixtures, the visual evidences showed no or very little sign of stripping; therefore the difference in energy based parameters of wet and dry limestone samples is expected to be low. The normalized energy based parameters meet this expectation, while the former energy based parameters do not (comparing the results in Figs 6 to 8 with the results in Table 5).

Since the normalized responses were obtained from the results of the same tests that had been conducted previously, the new introduced responses had the same full factorial design as the previous responses. The ANOVA was performed again on the new energy based responses according to the mentioned design. The results of the analysis are given in Table 6. It can be realized that the NFE and NDCSE in limestone mixtures are sensitive to aging, temperature change and moisture conditioning $(\mathrm{P}<0.1)$; however the responses dependency on temperature and aging is much stronger than their dependency on moisture conditioning. This finding was supported by the visual inspections; as no stripping was detected in the limestone mixtures here, but they were temperature susceptible and their failure mode went through some changes after aging. The ANOVA for granite mixtures also show a very good correlation between the responses and the temperature and moisture conditioning factors. Aging does not seem to be an influencing factor (as much as the other two factors) on the normalized energy responses in granite mixtures here. To sum up, it might be concluded that normalized energy based responses are ap-

Table 6. Results of ANOVA test on sensitivity of different responses to independent factors

\begin{tabular}{|c|c|c|c|c|c|c|c|}
\hline Mixture type & Dependent variable & Independent variable & DF & Sum of square & Mean square & $\mathrm{F}$ & $\mathrm{P}$ \\
\hline \multirow{11}{*}{ Limestone } & \multirow{4}{*}{ NFE } & Aging Condition & 1 & 0.01137 & 0.01137 & 11.270 & 0.002 \\
\hline & & Testing Temperature & 2 & 1.93654 & 0.96827 & 959.890 & 0.000 \\
\hline & & Saturation Condition & 1 & 0.00359 & 0.00359 & 3.560 & 0.068 \\
\hline & & Error & 31 & 0.03127 & 0.00101 & & \\
\hline & \multirow{4}{*}{ NEE } & Aging Condition & 1 & 0.000163 & 0.000163 & 13.220 & 0.001 \\
\hline & & Testing Temperature & 2 & 0.002315 & 0.001157 & 93.650 & 0.000 \\
\hline & & Saturation Condition & 1 & $2 \mathrm{E}-07$ & $2 \mathrm{E}-07$ & 0.020 & 0.893 \\
\hline & & Error & 31 & 0.000383 & $1.24 \mathrm{E}-05$ & & \\
\hline & \multirow{3}{*}{ NDCSE } & Aging Condition & 1 & 0.0088 & 0.0088 & 9.410 & 0.004 \\
\hline & & Testing Temperature & 2 & 1.80526 & 0.90263 & 964.930 & 0.000 \\
\hline & & $\begin{array}{l}\text { Saturation Condition } \\
\text { Error } \\
\end{array}$ & $\begin{array}{l}1 \\
31\end{array}$ & $\begin{array}{l}0.00365 \\
0.029\end{array}$ & $\begin{array}{l}0.00365 \\
0.00094\end{array}$ & 3.900 & 0.057 \\
\hline \multirow{12}{*}{ Granite } & \multirow{4}{*}{ NFE } & Aging Condition & 1 & 0.06332 & 0.06332 & 1.890 & 0.179 \\
\hline & & Testing Temperature & 2 & 1.22438 & 0.61219 & 18.250 & 0.000 \\
\hline & & Saturation Condition & 1 & 0.61671 & 0.61671 & 18.380 & 0.000 \\
\hline & & Error & 31 & 1.04016 & 0.03355 & & \\
\hline & \multirow{4}{*}{ NEE } & Aging Condition & 1 & $3.2 \mathrm{E}-06$ & $3.2 \mathrm{E}-06$ & 0.320 & 0.578 \\
\hline & & Testing Temperature & 2 & 0.000375 & 0.000188 & 18.300 & 0.000 \\
\hline & & Saturation Condition & 1 & 0.000216 & 0.000216 & 21.100 & 0.000 \\
\hline & & Error & 31 & 0.000318 & $1.02 \mathrm{E}-05$ & & \\
\hline & \multirow{4}{*}{ NDCSE } & Aging Condition & 1 & 0.06241 & 0.06241 & 1.920 & 0.175 \\
\hline & & Testing Temperature & 2 & 1.18195 & 0.59098 & 18.210 & 0.000 \\
\hline & & Saturation Condition & 1 & 0.59383 & 0.59383 & 18.290 & 0.000 \\
\hline & & Error & 31 & 1.00626 & 0.03246 & & \\
\hline
\end{tabular}


propriate to evaluate mixtures' moisture sensitivity. Finally, it should be emphasized that the conclusions here are limited to the tests conducted during this research, and more experimental and/or field investigations are needed before making strong suggestions about using the introduced responses.

\section{Conclusions}

According to the IDT tests on aged and un-aged mixtures made of two types of aggregates at three levels of temperature, different responses of FE, EE and DCSE were obtained based on full factorial design method. After evaluating the sensitivity of the responses to the testing factors using ANOVA and comparing its results:

1) with the experimental tests and visual inspections of broken specimens, following conclusions were obtained:Fracture energy, elastic energy and dissipated creep strain energy might not be suitable responses to evaluate mixtures behaviour under different environmental conditions according to experimental tests and statistical analysis.

2) Modified energy responses (NFE, NEE, NDSCE) were obtained by normalizing the energy responses by the failure strain of IDT results. The introduced responses seemed to detect the testing factors (including the moisture conditioning and temperature) influence on specimens better than the common energy responses.

3) The recorded failure deformations were higher for moisture conditioned specimens than dry specimens in almost all combinations of test parameters.

Higher temperatures made the samples behave more as a plastic material than a fragile material. Samples became more prone to plastic deformation rather than fracture and the effect of moisture faded away at higher temperatures.

\section{References}

Alam, M. M.; Tandon, V.; Nazarian, S.; Tahmoressi, M. 1998. Identification of moisture-susceptible asphalt concrete mixes using modified environmental conditioning system, Transportation Research Record 1630: 106-116. http://dx.doi.org/10.3141/1630-13

Alshamsi, K. S. 2006. Development of a mix design methodology for asphalt mixtures with analytically formulated aggregate structures: PhD dissertation. The Department of Civil and Environmental Engineering, Louisiana State University, USA.

AASHTO R 30-02 Standard Practice for Mixture Conditioning of Hot-Mix Asphalt (HMA). The American Association of State Highway and Transportation Officials (AASHTO), 2010. $4 \mathrm{p}$.

AASHTO T096-02-UL Standard Method of Test for Resistance to Degradation of Small-Size Coarse Aggregate by Abrasion and Impact in the Los Angeles Machine. American Association of State Highway and Transportation Officials (AASHTO), 2006. 2 p.

AASHTO T104-99-UL Standard Method of Test for Soundess of Aggregate by Use of Sodium Sulfate or Magnesium Sulfate. American Association of State Highway and Transportation Officials (AASHTO), 2007. 9 p.
AASHTO T176-08-UL Standard Method of Test for Plastic Fines in Graded Aggregates and Soils by Use of the Sand Equivalent Test. American Association of State Highway and Transportation Officials (AASHTO), 2008. 13 p.

AASHTO TP9-96 Standard Test Method for Determining the Creep Compliance and Strength of Hot Mix Asphalt (HMA) Using the Indirect Tensile Test Device. American Association of State Highway and Transportation Officials (AASHTO), 1996. 4 p.

AASTO T182-84-UL Standard Method of Test for Coating and Stripping of Bitumen-Aggregate Mixtures. American Association of State Highway and Transportation Officials (AASHTO), 2005. 1 p.

ASTM D113-07 Standard Test Method for Ductility of Bituminous Materials. American Society for Testing and Materials (ASTM), USA, 2007. 4 p.

ASTM D1559-89 Test Method for Resistance of Plastic Flow of Bituminous Mixtures Using Marshall Apparatus (Withdrawn 1998). American Society for Testing and Materials (ASTM), USA, 1998. 3 p.

ASTM D2041/D2041M-11 Standard Test Method for Theoretical Maximum Specific Gravity and Density of Bituminous Paving Mixtures. American Society for Testing and Materials (ASTM), USA, 2011. 4 p.

ASTM D2726/D2726M-14 Standard Test Method for Bulk Specific Gravity and Density of Non-Absorptive Compacted Bituminous Mixtures. American Society for Testing and Materials (ASTM), USA, 2014. 4 p.

ASTM D36-06 Standard Test Method for Softening Point of Bitumen (Ring and Ball Apparatus). American Society for Testing and Materials (ASTM), USA, 2006. 4 p.

ASTM D4867/D4867M-09 Standard Test Method for Effect of Moisture on Asphalt Concrete Paving Mixtures. American Society for Testing and Materials (ASTM), USA, 2009. 5 p.

ASTM D5/D5M-13 Standard Test Method for Penetration of Bituminous Materials. American Society for Testing and Materials (ASTM), USA, 2013. 4 p.

ASTM D5821-13 Standard Test Method for Determining the Percentage of Fractured Particles in Coarse Aggregate. American Society for Testing and Materials (ASTM), USA, 2013. 6 p.

ASTM D70-09 Standard Test Method for Density of Semi-Solid Bituminous Materials (Pycnometer Method). American Society for Testing and Materials (ASTM), USA, 2009. 4 p.

Bagampadde, U.; Kaddu, D.; Kiggundu, B. M. 2013. Evaluation of rheology and moisture susceptibility of asphalt mixtures modified with low density polyethylene, International Journal of Pavement Research and Technology 6(3): 217-224.

Baek, C.; Underwood, B. S.; Kim, Y. R. 2012. Effects of oxidative aging on asphalt mixture properties, Transportation Research Record 2296: 77-85. http://dx.doi.org/10.3141/2296-08

Birgisson, B.; Roque R.; Page, G. C. 2003. Evaluation of water damage using hot mix asphalt fracture mechanics, Journal of Association of Asphalt Paving Technologists 72: 424-462.

BS 812 Testing aggregates. British Standards Institution, UK, 1975. $12 \mathrm{p}$.

Caro, S.; Masad, E.; Bhasin, A.; Little, D. N. 2008. Moisture susceptibility of asphalt mixtures, part 2: characterization and modelling, International Journal of Pavement Engineering 9(2): 99-114. http://dx.doi.org/10.1080/10298430701792144

Cheng, D. X.; Little, D. N.; Lytton, R. L.; Holste, J. C. 2002. Use of surface free energy properties of the asphalt-aggregate system to predict damage potential, Journal of Association of Asphalt Paving Technologists 71: 59-88. 
Cheng, D. X.; Little, D. N.; Lytton, R. L.; Holste, J. C. 2003. Moisture damage evaluation of asphalt mixtures by considering both moisture diffusion and repeated-load conditions, Transportation Research Record 1832: 42-49. http://dx.doi.org/10.3141/1832-06

Das, P. K. 2012. Thermally induced fracture performance of asphalt mixtures: MSc thesis. KTH Royal Institute of Technology, Sweden.

Grant, T. P. 2001. Determination of asphalt mixture healing rate using the Superpave indirect tensile test: MSc thesis. University of Florida, USA.

Howson, J.; Masad, E. A.; Bhasin, A.; Branco, V. C.; Arambula, E.; Lytton, R.; Little, D. 2007. System for the evaluation of moisture damage using fundamental material properties. Report No. FHWA/TX-07/0-4524-1. Texas Transportation Institute, The Texas A\&M University System, USA.

Jeremiah, T.; Farhana, R.; Mustaque, H. 2013. Investigation of aged hot-mix asphalt pavements. Report No. K-TRAN: KSU-09-2. Kansas Department of Transportation, USA.

Kanitpong, K.; Bahia, H. U. 2005. Relating adhesion and cohesion of asphalts to the effect of moisture on laboratory performance of asphalt mixtures, Transportation Research Record 1901: 33-43. http://dx.doi.org/10.3141/1901-05

Kim, J. S. 2002. Complex modulus from indirect tension resting: MSc thesis. University of Florida, USA.

Kim, Y. R. 2009. Modeling of asphalt concrete. ACSE Press, McGraw-Hill Construction, USA. 460 p.

Kim, S.; Coree, B. J. 2005. Evaluation of hot mix asphalt moisture sensitivity using the Nottingham asphalt test equipment. Report No. IHRB Project TR-483. Department of Civil, Construction, and Environmental Engineering, Iowa State University.

Kim, Y. R.; Daniel, J. S.; Wen, H. 2002. Fatigue performance evaluation of WesTrack asphalt mixtures using viscoelastic continuum damage approach. Research Project No. HWY0678. North Carolina Department of Transportation, USA.

Khalid, H. A.; Monney, O. K. 2009. Moisture damage potential of cold asphalt, International Journal of Pavement Engineering 10(5): 311-318.

http://dx.doi.org/10.1080/10298430802169838
Marasteanu, M. O.; Li, X.; Clyne, T. R.; Voller,V. R.; Timm, D. H.; Newcomb, D. E. 2004. Low temperature cracking of asphalt concrete pavements. Report No. MN/RC-2004-23. University of Minnesota, Department of Civil Engineering, Minneapolis, USA.

Momen, M. 2004. Complex modulus determination of asphalt concrete using indirect tension test: MSc thesis. North Carolina State University, USA.

Moraes, R.; Velasquez, R; Bahia, H. 2011. Measuring effect of moisture on asphalt-aggregate bond with the bitumen bond strength test, Transportation Research Record 2209: 70-81. http://dx.doi.org/10.3141/2209-09

Piratheepan, J.; Gnanendran, C. T.; Arulrajah, A. 2012. Determination of $\mathrm{C}$ and $\varphi$ from IDT and unconfined compression testing and numerical analysis, Journal of Materials in Civil Engineering 24(9): 1153-1164. http://dx.doi.org/10.1061/(ASCE)MT.1943-5533.0000493

Roque, R.; Birgisson, B.; Sangpetngam, B.; Zhang, Z. 2002a. Hot mix asphalt fracture mechanics: a fundamental crack growth law for asphalt mixtures, Journal of Association of Asphalt Paving Technologists 71: 957-1064.

Roque, R.; Birgisson, R.; Zhang, Z.; Sangpetngam, B.; Grant, T. $2002 \mathrm{~b}$. Implementation of SHRP indirect tension tester to mitigation cracking in asphalt pavements and overlays. UF project no. 4910450457912. Florida department of Transportation, University of Florida, USA.

Singh, D.; Zaman, M.; Commuri, S. Effect of long term oven aging on dynamic modulus of hot mix asphalt, in GeoFrontiers, 13-16 March 2011, Dallas, Texas, USA, 47734781.

Zhang, Z.; Roque, R.; Birgisson, B.; Sangpetngam, B. 2001. Identification and verification of a suitable crack growth law (with discussion), Journal of Association of Asphalt Paving Technologists 70: 206-241.

Zegeye, E. T.; Moon, K. H.; Turos, M.; Clyne, T. R.; Marasteanu, M. O. 2012. Low temperature fracture properties of polyphosphoric acid modified asphalt mixtures, Journal of Materials in Civil Engineering 24(8): 1089-1096. http://dx.doi.org/10.1061/(ASCE)MT.1943-5533.0000488

Amir MEHRARA. He is the PhD candidate of road and transportation engineering in the department of civil and environmental engineering at Amirkabir University of Technology. He has majored in road and transportation engineering in the MSc. degree in 2007 from the same university, and has got his BSc. degree in 2005 from Tabriz University. Since 2005 he has been involved in many researches about flexible pavements including their behavioural mechanism, distresses and mechanics of materials. He has also contributed in a number of consultancy projects in geometric design of highways and also design of the pavements. The asphalt mixtures stripping and healing potential is the main research area that he has been pursued during his PhD dissertation.

Ali KHODAII. He is a member of academia since 1986 when graduated with a PhD from Queen's University of Belfast and joined the department of civil and environmental engineering at Amirkabir University of Technology. He has been involved in teaching many transportation and highway engineering subjects at both graduate and undergraduate levels and has so far supervised many research students in their master and doctoral theses. Dr. Khodaii's publication in local and international journals covers a wide range of spectrum of research area from pavement materials, use of Geothynthetic materials in pavement structures, fundamental properties of flexible pavement materials, distress modes particularly stripping potential of such materials etc. His vast past experience has long been used in many consultancy projects in design of highway and airfield pavements. 